\title{
Eco-friendly polyvinyl alcohol (PVA)/bamboo charcoal (BC) \\ nanocomposites with superior mechanical and thermal properties
}

\author{
Mohanad Mousa, Yu Dong*, Ian J. Davies \\ Department of Mechanical Engineering, School of Civil and Mechanical Engineering, Curtin \\ University, GPO Box U1987, Perth, WA 6845, Australia
}

\begin{abstract}
Carbon-based nanofillers, such as carbon nanotubes (CNTs) and graphene sheets are considered as effective nanoreinforcements due to their unique structures and material performance. However, the utilisation of such nanofillers can be hindered owing to a high level of nanotoxicity via human inhalation and high material cost for CNTs, as well as the tendency to form agglomerates of graphene sheets in polymer matrices. Bamboo charcoals (BCs) are eco-friendly and sustainable carbon-based particles, which possess good affinity with polyvinyl alcohol (PVA), one of popular water soluble biopolymers, to achieve excellent properties of $\mathrm{PVA} / \mathrm{BC}$ nanocomposites. In particular, porous structures of $\mathrm{BC}$ particles enable polymeric molecules to easily penetrate with the strong internal bonding. In this study, fully eco-friendly PVA/BC nanocomposite films were successfully fabricated using a simple solution casting method to achieve the high dispersibility of BCs. With the inclusion of only $3 \mathrm{wt} \% \mathrm{BCs}$, tensile modulus and tensile strength of $\mathrm{PVA} / \mathrm{BC}$ nanocomposite films were enhanced by 70.2 and $71.6 \%$, respectively when compared with those of PVA films. Better thermal stability is manifested for resulting nanocomposite films as opposed to that of pristine PVA, which is evidenced by the maximum increase of $17.8 \%$ in the decomposition temperature at the weight loss of $80 \%$. It is anticipated that BCs can
\end{abstract}

\footnotetext{
* Corresponding author. Tel.: +61 89266 9055; fax: +61 892662681.

E-mail address: Y.Dong@curtin.edu.au (Y.Dong).
} 
compete against conventional carbon-based nanofillers with a great potential to be developed into eco-friendly nanocomposites used for thin-film packaging application.

Keywords: Polyvinyl alcohol (PVA); bamboo charcoals (BCs); nanocomposites; mechanical properties; thermal stability

\section{Introduction}

The annual global production of plastics is expected to exceed 300 million tons by 2015 [1]. However, the majority of these plastics belong to synthetic polymers such as polypropylene (PP), polyethylene (PE), and polystyrene (PS). Synthetic polymers include a huge amount of non-degradable wastes and cause a serious depletion of landfill capacities. [2] Furthermore, the disposal of synthetic polymers becomes more formidable considering that many of these polymers resist physical and chemical degradation [3], As such, synthetic polymers can be alleviated by developing biodegradable polymers such as water-soluble PVA, which has received considerable attention due to its favourable mechanical properties, thermal resistance, excellent flexibility [4] and recyclability, and bio-tribological properties [5]. It is also worth noting that these aforementioned properties of PVA make it a suitable material candidate for a wide range of biotechnological applications from tissue engineering, drug delivery, articular cartilage to biosensors[4-6].

In recent years, many researchers have focused on using nanomaterials or nanofillers to reinforce PVA in order to significantly enhance its mechanical and thermal properties, as well as biodegradability. Those nanofillers comprise montmorillonite (MMT) clays[7-11], halloysite nanotubes (HNTs) [12-15], CNTs [16,17], graphene sheets,[18-21] cellulose nanocrystals [22-24], laponite [25] and nanodiamond [26].

Notwithstanding the effective reinforcement role of CNTs, major drawback of CNTs lies in their nanotoxic characteristic to accumulate in cytoplasm and finally destroy human cells in a 
suitable inhalational condition in addition to high production cost. [2] On the other hand, graphene sheets can also undergo the limited use owing to their high tendency to form agglomerates[27].

More recently, the emphasis has been laid on material development to utilise bamboo charcoals (BCs) as carbon-based eco-friendly and functional materials. Such BC particles are generally made from rapidly growing bamboo carbonised at the high temperature about $1000^{\circ} \mathrm{C}$ under the anerobic condition [28]. BCs consist of short stacks of graphene sheets in connection to form 3D networks with innumerable lengthwise and crosswise pores [29-30]. Moreover, their volumetric porosity, mineral constituents and absorption efficiency are about 5, 8 and 10 times more than those of wood charcoals.[30] In particular, the inner surface area of BCs is about $250-390 \mathrm{~m}^{2} / \mathrm{g}$, as opposed to $10 \mathrm{~m}^{2} / \mathrm{g}$ in the case of wood charcoals [31-32]. These remarkable features of BCs lead to various applications including suppliers for negative ions [33] humidity regulators [34], water purification [35], oxidation prevention, anti-bacterial [36] and anti-fungal features and breathability[32]. The humidity control of BCs enables them to inhibit the growth of bacteria and fungi to maintain a fresh food level $[34,37]$. This approach is very important for food packaging industries so as to increase the shelf life of products. Additionally, BCs are also capable of absorbing far more infrared energy from environment, which is emitted to support the cell activation for efficient human blood circulation [38]. The elemental inclusion such as calcium, potassium, sodium and iron within BCs is essential for the purposes of food cooking, baking and storage $[39,40]$. In a nanocomposite system, $\mathrm{BC}$ morphology displays a wide range of pore distribution from $<1 \mathrm{~nm}$ to $1 \mu \mathrm{m}$. The walls of basic unit inside BCs, known as parenchyma, are very rough along with their smooth outer surfaces to make the whole charcoals quite hard. A great many pores associated with rough walls inside BCs may be able to promote the effective interfacial bonding between fillers and polymer matrices, thus resulting in improved mechanical 
properties of composite materials. This is believed to arise from the penetration of polymeric chains into internal pores of BCs leading to strong mechanical bonding in addition to the hydrogen bonding of pores. Main research work has focused on BCs as microparticles to reinforce polymers in composite systems such as polylactic acid (PLA)/BC composites[41], ultra-high molecular weight polyethylene (UHMWPE)/BC composites [42] and polyaniline (PANI)/BC composites[43]. Up to now, very limited published work is available regarding the effect of $\mathrm{BC}$ nanoparticles on mechanical and thermal properties of PVA/BC composite films. In this study, a simple synthetic approach of PVA/BC nanocomposite films was employed based on the solution casting method. The effects of $\mathrm{BC}$ content on material characterisation, mechanical and thermal properties of final nanocomposite films were investigated in detail to evaluate the potential of $\mathrm{BCs}$ as new reinforcing nanofillers used in the eco-friendly packaging field.

\section{Experimental details}

\subsection{Materials}

PVA biopolymer MFCD00081922 (average molecular weight $M_{w}=89000-98000 \mathrm{~g} / \mathrm{mol}$ and the degree of hydrolysis at over 99\%) was obtained from Sigma Aldrich Pty. Ltd, NSW, Australia. BC nanoparticles (particle size: $700-800 \mathrm{~nm}$ ) used in this study were purchased from Jiangshan Luyi Bamboo Charcoals Co., Ltd, China.

\subsection{Fabrication of PVA/BC nanocomposite films}

PVA/BC nanocomposites were prepared by a simple solution casting method. Initially $5 \%$ PVA aqueous solution for stock was prepared by dissolving 10 g PVA into $190 \mathrm{ml}$ deionised water via vigorous magnetic stirring at $400 \mathrm{rpm}$ and $90^{\circ} \mathrm{C}$ for $3 \mathrm{~h}$ until PVA was completely dissolved. The aqueous suspension of BC nanoparticles was obtained using mechanical 
mixing in deionised water at $405 \mathrm{rpm}$ and $40^{\circ} \mathrm{C}$ for $2 \mathrm{~h}$. This was followed by the ultrasonication with the aid of an ultrasonic cleaning unit ELMA Ti-H-5 at $25 \mathrm{kHz}$ and $40^{\circ} \mathrm{C}$ with the power intensity of $70 \%$ for $1 \mathrm{~h}$. The $\mathrm{BC}$ contents in range from $0,3,5$ to $10 \mathrm{wt} \%$ were obtained by adding different amounts of PVA. BC aqueous suspension was then gradually dripped in a dropwise manner into PVA solutions, simultaneously subjected to mechanical mixing at $405 \mathrm{rpm}$ and $40^{\circ} \mathrm{C}$ for $2 \mathrm{~h}$. Then their mixture was stirred at $400 \mathrm{rpm}$ and $90^{\circ} \mathrm{C}$ for $1 \mathrm{~h}$ prior to the subsequent similar sonication for $30 \mathrm{~min}$ to achieve uniform dispersion of BC nanoparticles. Finally, $20 \mathrm{ml}$ solution was cast on a glass petri dish and further allowed to dry using an air-circulating oven at $40^{\circ} \mathrm{C}$ for $48 \mathrm{~h}$. Then $\mathrm{PVA} / \mathrm{BC}$ nanocomposite films were peeled off from petri dishes and stored in a desiccator with underneath silicon gels prior to further material testing and analysis.

\subsection{Material Characterisation}

Tensile properties of PVA/BC nanocomposite films were measured on a LIoyd EZ50 universal testing machine with a crosshead speed of $10 \mathrm{~mm} / \mathrm{min}$ (initial gauge length: 50 $\mathrm{mm})$. For each material batch, six samples were tested and average data with associated standard deviations were calculated accordingly.

The surface morphology of fractured tensile testing samples was observed by a field emission scanning electron microscope (FESEM, Zeiss NEON 40 EsB Cross Beam) at an accelerating voltage of $5 \mathrm{kV}$. These samples were platinum coated prior to surface morphological analysis.

Thermal stability of nanocomposite films was examined with a TGA/DSC 1 STARe system (METTLER TOLEDO) from 35 to $700^{\circ} \mathrm{C}$ at a scan rate of $10^{\circ} \mathrm{C} / \mathrm{min}$ under argon atmosphere (flow rate: $25 \mathrm{ml} / \mathrm{min}$ ). 
Carbon, hydrogen, nitrogen and oxygen contents of BCs were measured by a CHNS/O element analyser at $900^{\circ} \mathrm{C}$ (Perkin Elmer 2400 Series II).

Fourier transform infrared (FTIR) spectrometry (100FT-IR Spectrometer-Perkin Elmer) was employed to characterise PVA, BC nanoparticles and PVA/BC nanocomposites at wave numbers ranging from $650-4000 \mathrm{~cm}^{-1}$ with a resolution of $4 \mathrm{~cm}^{-1}$ using an attenuated total reflectance (ATR) method.

XRD analysis was conducted via Bruker D8 Advance Diffractometer. The X-ray source was $\mathrm{Ni}$-filtered $\mathrm{Cu}-\mathrm{K} \alpha$ radiation at the accelerating voltage and current of $40 \mathrm{kV}$ and $40 \mathrm{~mA}$ with the X-ray spectra recorded in range of $10^{\circ}-50^{\circ}$ at the scan rate of $0.015^{\circ} / \mathrm{sec}$.

\section{Result and discussion}

\subsection{BC characterisation}

Chemical composition of BCs generally consist of carbon, oxygen, hydrogen, nitrogen and a small amount of ash. [44]. In this study, the carbon content of BCs is $80.04 \%$, which is in good accordance with previous results obtained by Li et al, [44]. It is suggested that BCs could be regarded as good carbon-based fillers for effective reinforcements in nanocomposite systems. Oxygen, hydrogen and nitrogen contents for $\mathrm{BCs}$ are less pronounced $(\mathrm{O} \%: 6.93 \%$, $\mathrm{H} \%$ : $2.54 \%$ and N\%: $0.52 \%$ ). Moreover, surface area and pore volume have also been detected for $\mathrm{BCs}$ in order to evaluate $\mathrm{BC}$ absorption capacity within polymer matrices. Experimental results reveal that all three major surface areas including Brunauer-EmmettTeller $(\mathrm{BET})$ surface area $\left(S_{B E T}\right)$, micropore area $\left(S_{m i c r o}\right)$ and external surface area $\left(S_{\text {ext }}\right)$ are 527.41, 390.84 and $136.57 \mathrm{~m}^{2} \mathrm{~g}^{-1}$, respectively. As such, BCs demonstrate much better absorption capability within polymer matrices, thus resulting in more efficient load transfer from matrices to fillers as mentioned elsewhere [45]. 
The FTIR of BC particles was carried out to investigate the surface functionality of asreceived particles, Figure 1 (a). The peak at about 2439.6 is assigned to the $\mathrm{C} \equiv \mathrm{H}$ stretching [46]. Whereas the peaks at about $1566.6 \mathrm{~cm}^{-1}$ represent $\mathrm{C}=\mathrm{C}$ vibration in an aromatic system. [45] The peak at $1695.9 \mathrm{~cm}^{-1}$ is corresponding to the $\mathrm{C}=\mathrm{O}$ reign primarily for ionisable carboxyl groups as an indicator of surface hydrophilicity [47]. The band existing at 1111.1 $\mathrm{cm}^{-1}$ is ascribed to the axial deformation of $\mathrm{C}-\mathrm{O}$ band. Moreover, the band at $872.1 \mathrm{~cm}^{-1}$ is referred to as the $\mathrm{C}-\mathrm{H}$ bending (in plane). The out of plane $-\mathrm{OH}$ bending is also designated by the band appearance at $743.6 \mathrm{~cm}^{-1}$ for BCs. Finally, missing $-\mathrm{OH}$ peak at $3350 \mathrm{~cm}^{-1}$ in $\mathrm{BC}$ spectra infers that BCs possess much lower moisture and alcohol contents [48].

Moreover, XRD pattern of BCs, as depicted in Figure 1(b), reveal the existence of two broad peaks. The board peaks at $2 \theta=22.9^{\circ}$ is corresponding to the sharp peaks of graphite, which is assigned to the (002) diffraction plane [49]. Moreover, second broad peak at $2 \theta=43.6^{\circ}$ characterises 2D in-plane symmetry along with graphene layers, corresponding to (100) diffraction plane.

\subsection{PVA/BC Composite film properties and characterization}

FTIR analysis was carried out to evaluate possible interactions between PVA and BCs, as illustrated in Figure 2 (a), indicating that the assigned $-\mathrm{OH}$ stretching and $-\mathrm{C}-\mathrm{OH}$ stretching bands can be used to form hydrogen bonding. The wave number band ranging from 3100$3500 \mathrm{~cm}^{-1}$ is assigned to the strong hydroxyl band for free and hydrogen bonded alcohols, which shifts to a lower number after the incorporation of BCs into PVA matrices. For instance, the wave number at $3271.5 \mathrm{~cm}^{-1}$ for pure PVA film shifts to $3262.0 \mathrm{~cm}^{-1}$ in the case of $\mathrm{PVA} / 3 \mathrm{wt} \% \mathrm{BC}$ composites, which is in good agreement with previous result for PVA/graphene nanocomposites [41]. This phenomenon is attributed to the dissociation of hydrogen bonding between hydroxyl groups in PVA and subsequent formation of hydrogen bonding between $-\mathrm{OH}$ groups within $\mathrm{BCs}$ and PVA matrices [50, 51]. Moreover, the wide 
peak range between 2940 and $2845 \mathrm{~cm}^{-1}$ is known to be associated with $\left(-\mathrm{CH}_{2}-\right)$ asymmetric and symmetric stretching, respectively. The increasing tendency of peaks implies that $\mathrm{BC}$ nanoparticles are strongly bonded to PVA matrices owing to the close connection formed by hydrogen bonding, which is similar to PVA/graphene oxide (GO) nanocmposites [52].

XRD patterns for pure PVA and PVA/BC composite films are shown in Figure 2(b). Pure PVA films reveal a strong maximum diffraction peak at $2 \theta=19.7^{\circ}$, corresponding to the total crystalline plane (101) of PVA. [53]. Moreover, XRD peaks for PVA/BC composites present a slight shift to larger diffraction angles, which is mostly likely due to the interaction between PVA and BCs.

Mechanical properties of PVA/BC nanocomposite films in term of tensile strength, tensile modulus and elongation at break are shown in Figure 2(c) and Table 1. It can be seen that the tensile modulus of nanocomposite films increases with increasing the $\mathrm{BC}$ content. $\mathrm{PVA} / \mathrm{BC}$ nanocomposites reinforced with $3 \mathrm{wt} \%$ BCs have achieved a tensile modulus of $3.54 \mathrm{GPa}$ with an modulus increase of $70.2 \%$ compared to that of neat PVA. This result can be interpreted by the restriction of BCs to the chain motion of PVA matrices, thus decreasing PVA deformation capacity in the elastic region to make nanocomposites much stiffer [50-52]. In general, tensile strength is an indicator in mechanical properties to evaluate the interfacial bonding between fillers and polymer matrices within composite materials. As illustrated in Figure 2(c), tensile strengths of PVA/BC nanocomposites increased at $\mathrm{BC}$ contents from 0 to $3 \mathrm{wt} \%$, and then they decreased at the higher content levels up to $10 \mathrm{wt} \%$. With the inclusion of $3 \mathrm{wt} \% \mathrm{BCs}$, tensile strength of nanocomposites was increased by $71.6 \%$ when compared with that of pure PVA, which is ascribed to the good interfacial bonding between welldispersed BC nanoparticles at low contents and PVA matrices. This is because uniformly dispersed $\mathrm{BCs}$ generate large surface areas to promote effective load transfer from nanofillers to PVA matrices. In addition, porous structures of BCs enable the mobility of polymeric 
chains into internal pores and gaps of nanoparticles, leading to strong mechanical adhesion between nanofillers and PVA matrices. When the BC content is beyond $3 \mathrm{wt} \%$, tensile strengths of nanocomposites declined remarkably though they were still higher than that of neat PVA. This strength reduction trend is most likely due to the occurrence of more $\mathrm{BC}$ aggregates, acting as high stress concentration sites prone to mechanical failure with much weaker interfacial bonding. The elongation at break appeared to significantly decrease with increasing the $\mathrm{BC}$ content, Table 1. The reduced extensibility of PVA matrices lies in the resistance of rigid $\mathrm{BCs}$, which tends to be more severe when $\mathrm{BC}$ aggregates are formed at high content levels. Due to the BC agglomeration, partial particle-particle and PVA-particle separations may occur, thus obstructing the stress propagation when tensile stress is applied [41].

The $\mathrm{BC}$ dispersion status within continuous PVA matrices has been examined by scanning electron microscopy (SEM). SEM images on tensile fracture surfaces of neat PVA and PVA/BC nanocomposite films are depicted in Figure 3. Neat PVA possesses fairly smooth fracture surfaces without any obviously preferential orientation, Figure 3(a). Whereas, fracture surfaces of PVA/BC nanocomposites tend to be much rougher with a clear sign of embedded BC nanoparticles. In particular, layered structures and well dispersed BCs are presented on fracture surfaces of PVA nanocomposites reinforced with $3 \mathrm{wt} \% \mathrm{BC}$ nanoparticles, Figure 3(b). Good interfacial bonding between BCs and PVA matrices is clearly demonstrated for an effective load transfer, which is in good accordance with previously obtained maximum tensile strength of corresponding nanocomposites in Figure 2(c). Another plausible reason is associated with $\mathrm{BC}$ porous structures, assisting in the mobility of polymeric chains into internal pores and BC gaps. It leads to strong adhesion between polymer matrices and BC fillers. As shown in Figures 3(c) and (d), with increasing the $\mathrm{BC}$ content from 5 to $10 \mathrm{wt} \%$, the interparticle distance can be significantly reduced 
owing to large amounts of particle agglomerates. As a result, the formation of local networks of $\mathrm{BC}$ particles that work as stress concentration sites prone to mechanical failure takes place, thus lowering tensile strengths of nanocomposites depicted in Figure 2(c).

It is interesting to note that mechanical performance of PVA/BC nanocomposites is not the only aspect for the property enhancement. Thermal stability of such nanocomposites has also been improved significantly with increasing the BC content. TGA and DTG results for pure PVA and its nanocomposites with the BC contents of 3, 5 and $10 \mathrm{wt} \%$ are depicted in Figure 4 and Table 2. Both pure PVA and PVA/BC nanocomposites can decompose in a three-step process according to previous literatures [20, 41]. First of all, the evaporation of trapped water occurs at the temperature range from $50-176^{\circ} \mathrm{C}$. The second stage at $200-400^{\circ} \mathrm{C}$ involves the elimination reaction of water as well as the formation of polyacetylene structures. Finally, further degradation of polyene residues to yield carbons and hydrocarbons takes place at $400-550^{\circ} \mathrm{C}$. TGA curves of nanocomposites have gradually shifted toward a higher temperature range when the $\mathrm{BC}$ content increases from 0 to $10 \mathrm{wt} \%$, as evidenced by unanimously higher $T_{5 \%}, T_{80 \%}$ and $\mathrm{T}_{d}$ values. Such a phenomenon indicates that the presence of BC nanoparticles can delay PVA thermal degradation, which may act as material barriers to hinder volatile degradation products $[26,43]$.

\section{Conclusion}

PVA/BC nanocomposite films were successfully prepared with a simple eco-friendly solution casting method. The SEM images confirm homogenous BC dispersion has been achieved, especially at the low $\mathrm{BC}$ content from 3 to $5 \mathrm{wt} \%$ in PVA/BC nanocomposites. Significant enhancement of mechanical properties of nanocomposites was detected at low BC content levels in range from 0 to $3 \mathrm{wt} \%$. The addition of $\mathrm{BC}$ nanoparticles from 0 to $3 \mathrm{wt} \%$ was found to significantly increase tensile strength and tensile modulus of PVA/BC 
nanocomposites by 71.6 and $70.2 \%$, respectively. TGA results reveal that the incorporation of BC nanoparticles can greatly improve the thermal stability of nanocomposite films. The increase in the $\mathrm{BC}$ content leads to consistently higher $T_{5 \%}, T_{80} \%$ and $\mathrm{T}_{d}$. It is anticipated that such PVA/BC nanocomposites with superior mechanical and thermal properties prepared in this study can become fully biodegradable and biocompatible composite materials used in future widespread applications.

\section{Acknowledgements}

The first author acknowledges the Higher Committee for Education Development (HCED) in Iraq to award the research scholarship for his $\mathrm{PhD}$ studies at Curtin University, Australia.

\section{References}

[1] Reddy, MM, Vivekanandhan, S., Misra, M., Bhatia, S K, Mohanty, AK. Biobased plastics and bionanocomposites: Current status and future opportunities. Prog. Polym. Sci. 2013; 38: 1653-1689.

[2] Mousa, MH, Dong, Y. Davies, IJ. Recent Advances in Bionanocomposites: Preparation, Properties, and Applications. Inter. J. Polym. Mater. Polym. Biomater. 2016; 65: 225254.

[3] Leja, K., Lewandowicz, G. Polymer biodegradation and biodegradable polymers a review. Polish J. of Environ. Stud. 2010; 19: 255-266.

[4] Huang, D., Wang, A. Non-covalently functionalized multiwalled carbon nanotubes by chitosan and their synergistic reinforcing effects in PVA films. RSC Adv. 2012; 3:12101216.

[5] Yang, X., Zhang, X., Liu, Z., Ma, Y., Huang, Y., Chen, Y. High-efficiency loading and controlled release of doxorubicin hydrochloride on graphene oxide. J. Phys. Chem. C 2008; 112: 17554-17558. 
[6] Espinosa, HD, Rim, JE, Barthelat, F., Buehler, MJ. Merger of structure and material in nacre and bone-Perspectives on de novo biomimetic materials. Prog. Mater. Sci. 2009; 54: 1059-1100.

[7] Sapalidis, AA, Katsaros, FK, Kanellopoulos, NK. 2011. PVA/montmorillonite nanocomposites: development and properties. J. Cuppoletti (ed.), Nanocomposites and polymers with analytical methods, InTech, Rijeka, Croatia, pp. 29-50.

[8] Paranhos, CM, Dahmouche, K., Zaioncz, S., Soares, B G, Pessan, LA. Relationships between nanostructure and thermomechanical properties in poly (vinyl alcohol)/montmorillonite nanocomposite with an entrapped polyelectrolyte. J. Polym. Sci. B Polym. Phys. 2008; 46: 2618-2629.

[9] Mallakpour, S., Dinari, M. Biomodification of Cloisite $\mathrm{Na}+$ with L-methionine amino acid and preparation of poly (vinyl alcohol)/organoclay nanocomposite films. J. Appl. Polym. Sci. 2012; 124: 4322-4330.

[10] Jose, T., George, SC, Maria, HJ, Wilson, R., Thomas, S. Effect of bentonite clay on the mechanical, thermal, and pervaporation performance of the poly (vinyl alcohol) nanocomposite membranes. Ind. Eng. Chem. Res. 2014; 53:16820-16831.

[11] Lai, JCH, Rahman, M., Hamdan, S., Liew, FK, Hossen, M. Impact of nanoclay on physicomechanical and thermal analysis of polyvinyl alcohol/fumed silica/clay nanocomposites. J. Appl. Polym. Sci. 2015; 132: 1-7

[12] Fujii, K., Nakagaito, A N, Takagi, H., Yonekura, D. Sulfuric acid treatment of halloysite nanoclay to improve the mechanical properties of PVA/halloysite transparent composite films. Compos. Interfaces 2014; 21: 319-327.

[13] Swapna, VP, Suresh, KI, Saranya, V., Rahana, MP, Stephen, R. Thermal properties of poly (vinyl alcohol)(PVA)/halloysite nanotubes reinforced nanocomposites. Int. J. Plast. Technol. 2015; 19:124-136. 
[14] Khoo, WS, Ismail, H., Ariffin, A. Tensile, swelling, and oxidative degradation properties of crosslinked polyvinyl alcohol/chitosan/halloysite nanotube composites. Inter. J. Poly. Mater. Polym. Biomater. 2013; 62: 390-396.

[15] Qiu, K., Netravali, AN. Halloysite nanotube reinforced biodegradable nanocomposites using noncrosslinked and malonic acid crosslinked polyvinyl alcohol. Polym. Compos. 2013; 34: 799-809.

[16] Du, FP, Ye, EZ, Yang, W., Shen, TH, Tang, CY, Xie, XL, Law, WC. Electroactive shape memory polymer based on optimized multi-walled carbon nanotubes/polyvinyl alcohol nanocomposites. Compos. Part B, 2015; 68:170-175.

[17] Chen, W., Tao, X., Xue, P., Cheng, X. 2005. Enhanced mechanical properties and morphological characterizations of poly (vinyl alcohol)-carbon nanotube composite films. Appl. Surf. Sci. 2005; 252: 1404-1409.

[18] Moradi, M., Mohandesi, JA., Haghshenas, DF. Mechanical properties of the poly (vinyl alcohol) based nanocomposites at low content of surfactant wrapped graphene sheets. Polymer, 2015; 60: 207-214.

[19] Liang, J., Huang, Y., Zhang, L., Wang, Y., Ma, Y., Guo, T., Chen, Y. 2009. Molecularlevel dispersion of graphene into poly (vinyl alcohol) and effective reinforcement of their nanocomposites. Adv. Funct. Mater. 2009; 19: 2297-2302.

[20] Sun, Y., Shi, G. Graphene/polymer composites for energy applications. J. Polym. Sci. B Polym. Phys. 2013; 51: 231-253.

[21] Zhu, Y., Wang, H., Zhu, J., Chang, L., Ye, L. Nanoindentation and thermal study of polyvinylalcohol/graphene oxide nanocomposite film through organic/inorganic assembly. Appl. Surf. Sci. 2015; 349:27-34 
[22] Cheng, Q., Wang, S., Tong, Z. 2015. Poly (Vinyl Alcohol) Cellulose Nanocomposites. K. Kar, J. Pandey, S. Rana (ed.), In Handbook of Polymer Nanocomposites. Processing, Performance and Application, Springer, Berlin Heidelberg, pp. 433-447.

[23] Li, HZ, Chen, SC, Wang, YZ. Preparation and characterization of nanocomposites of polyvinyl alcohol/cellulose nanowhiskers/chitosan. Compos. Sci. Technol. 2015; 115: $60-65$.

[24] Leitão, AF, Silva, JP, Dourado, F., Ama, M. Production and characterization of a new bacterial cellulose/poly (vinyl alcohol) nanocomposite. Materials, 2013; 6: 1956-1966.

[25] Ren, W., Wu, R., Guo, P., Zhu, J., Li, H., Xu, S., Wang, J. Preparation and characterization of covalently bonded PVA/Laponite/HAPI nanocomposite multilayer freestanding films by layer-by-layer assembly. J. Polym. Sci. B Polym. Phys. 2015;53: $545-551$.

[26] Morimune, S., Kotera, M., Nishino, T., Goto, K., Hata, K., Poly (vinyl alcohol) nanocomposites with nanodiamond. Macromolecules 2011; 44: 4415-4421.

[27] Putz, KW, Compton OC, Palmeri, MJ, Nguyen, ST, Brinson, LC. High-nanofillercontent graphene oxide-polymer nanocomposites via vacuum-assisted selfassembly, Adv. Funct. Mater. 2010; 20: 3322-3329.

[28] Liao, P., Ismael, ZM, Zhang, W., Yuan, S., Tong, M., Wang, K., Bao, J. Adsorption of dyes from aqueous solutions by microwave modified bamboo charcoal. Chem. Eng. J. 2012; 195: 339-346.

[29] Singh, K., Singh, RS, Rai, BN, Upadhyay, SN. Biofiltration of toluene using wood charcoal as the biofilter media. Bioresour. Technol. 2010; 101: 3947-3951.

[30] Asada, T., Ohkubo, T., Kawata, K., Oikawa, K., Ammonia adsorption on bamboo charcoal with acid treatment. J. Health Sci. 2006; 52: 585-589. 
[31] Lou, C. W., Lin, CW, Lei, CH, Su, KH, Hsu, CH, Liu, ZH, Lin, JH. PET/PP blend with bamboo charcoal to produce functional composites. J. Mater. Process. Technol. 2007; 192:428-433.

[32] Ho, MP, Lau, KT, Wang, H., Hui, D. Improvement on the properties of polylactic acid (PLA) using bamboo charcoal particles. Compos. Part B, 2015; 81:14-25.

[33] Yeh, JT, Hsiung, HH, Wei, W., Zhu, P., Chen, KN, Jiang, T. Negative air ion releasing properties of tourmaline/bamboo charcoal compounds containing ethylene propylene diene terpolymer/polypropylene composites. J. Appl. Polym. Sci. 2009; 113: 1097-1110.

[34] Zhao, RS, Wang, X., Yuan, JP, Lin, JM. Investigation of feasibility of bamboo charcoal as solid-phase extraction adsorbent for the enrichment and determination of four phthalate esters in environmental water samples. J. Chromatogr. A 2008; 1183: 15-20.

[35] Mizuta, K., Matsumoto, T., Hatate, Y., Nishihara, K., Nakanishi, T. Removal of nitratenitrogen from drinking water using bamboo powder charcoal. Bioresour. Technol. 2004; 95: 255-257.

[36] Li, X., Lei, B., Lin, Z., Huang, L., Tan, S., Cai, X. The utilization of bamboo charcoal enhances wood plastic composites with excellent mechanical and thermal properties. Mater. Des. 2014; 53: 419-424.

[37] Nitayaphat, W., Jiratumnukul, N., Charuchinda, S., Kittinaovarat, S., Mechanical properties of chitosan/bamboo charcoal composite films made with normal and surface oxidized charcoal. Carbohydr. Polym. 2009; 78: 444-448.

[38] Yang, FC, Wu, KH, Lin, WP, Hu, MK. Preparation and antibacterial efficacy of bamboo charcoal/polyoxometalate biological material. Microporous Mesoporous Mater. 2009; 118: 467-472. 
[39] Kamada, K. Study on healthy housing using recycled organic industrial waste first report: overview of trends in the development of the latest technology and new materials in Japan. No. 32, Hokkaido Bunkyo University; 2008.

[40] Ho, MP, Lau, KT, Wang, H., Hui, D. Improvement on the properties of polylactic acid (PLA) using bamboo charcoal particles. Compos. Part B 2015; 81: 14-25.

[41] You, Z., Li, D. Highly filled bamboo charcoal powder reinforced ultra-high molecular weight polyethylene. Mater. Lett. 2014; 122: 121-124.

[42] Wu, KH., Ting, TH, Wang, GP, Yang, CC, Tsai, CW. Synthesis and microwave electromagnetic characteristics of bamboo charcoal/polyaniline composites in $2-$ 40GHz. Synth. Met. 2008; 158: 688-694.

[43] Ma, HL, Zhang, L., Zhang, Y., Wang, S., Sun, C., Yu, H., Zhai, M. Radiation preparation of graphene/carbon nanotubes hybrid fillers for mechanical reinforcement of poly (vinyl alcohol) films. Radiat. Phys. Chem. 2016; 118: 21-26.

[44] Li, S., Li, X., Chen, C., Wang, H., Deng, Q., Gong, M., Li, D. Development of electrically conductive nano bamboo charcoal/ultra-high molecular weight polyethylene composites with a segregated network. Compos. Sci. Technol. $2016 ; 132: 31-37$.

[45] She, B., Tao, X.; Huang, T.; Lu, G.; Zhou, Z.; Guo, C.; Dang, Z. Effects of nano bamboo charcoal on PAHs-degrading strain sphingomonas sp. GY2B. Ecotox. Environ. Safe. $2016 ; 125: 35-42$.

[46] Fu, D., Zhang, Y., Lv, F., Chu, P. K., Shang, J. Removal of organic materials from TNT red water by bamboo charcoal adsorption. Chem. Eng. J. 2012; 193-194 : 39-49.

[47] Lorenzoni, M., Evangelio, L., Verhaeghe, S., Nicolet, C., Navarro, C., Pérez-Murano, F. Assessing the local nanomechanical properties of self-assembled block copolymer thin films by peak force tapping. Langmuir 2015; 31: 11630-11638. 
[48] Das, O., Sarmah, A. K., Bhattacharyya, D. A novel approach in organic waste utilization through biochar addition in wood/polypropylene composites. Waste Manage. 2015; 38 : 132-140.

[49] Li, S., Li, X., Deng, Q., Li, D. Three kinds of charcoal powder reinforced ultra-high molecular weight polyethylene composites with excellent mechanical and electrical properties. Mater. Des. 2015; 85 : 54-59.

[50] Yang, X., Li, L., Shang, S., Tao, XM. Synthesis and characterization of layer-aligned poly (vinyl alcohol)/graphene nanocomposites. Polymer 2010; 51: 3431-3435.

[51] Lu, L., Sun, H., Peng, F., Jiang, Z. Novel graphite-filled PVA/CS hybrid membrane for pervaporation of benzene/cyclohexane mixtures. J. Membr. Sci. 2006; 281: 245-252.

[52] Cheng, HKF., Sahoo, NG, Tan, YP, Pan, Y., Bao, H., Li, L., Zhao, J. Poly (vinyl alcohol) nanocomposites filled with poly (vinyl alcohol)-grafted graphene oxide. ACS Appl. Mater. Interfaces 2012; 4: 2387-2394.

[53] Zhang J, Lei W, Liu D, Wang X. Synergistic influence from the hybridization of boron nitride and graphene oxide nanosheets on the thermal conductivity and mechanical properties of polymer nanocomposites. Compos. Sci. Technol. 2017; 151: 252-257. 


\section{List of Figures}

Fig. 1. Characterisation of individual BC particles (a) FTIR spectrum and (b) XRD pattern.

Fig. 2. (a) FTIR spectra, (b) XRD patterns and (c) mechanical properties of PVA/BC nanocomposite films at different BC contents: tensile modulus and tensile strength.

Fig. 3 SEM micrographs of fracture surfaces: (a) PVA, (b) PVA/ 3 wt $\%$ BC nanocomposites, (c) PVA/ $5 \mathrm{wt} \%$ BC nanocomposites and (d) PVA/ $10 \mathrm{wt} \%$ BC nanocomposites.

Fig. 4 Thermograms of PVA/BC nanocomposite films: (a) TGA curves and (b) DTG curves. 


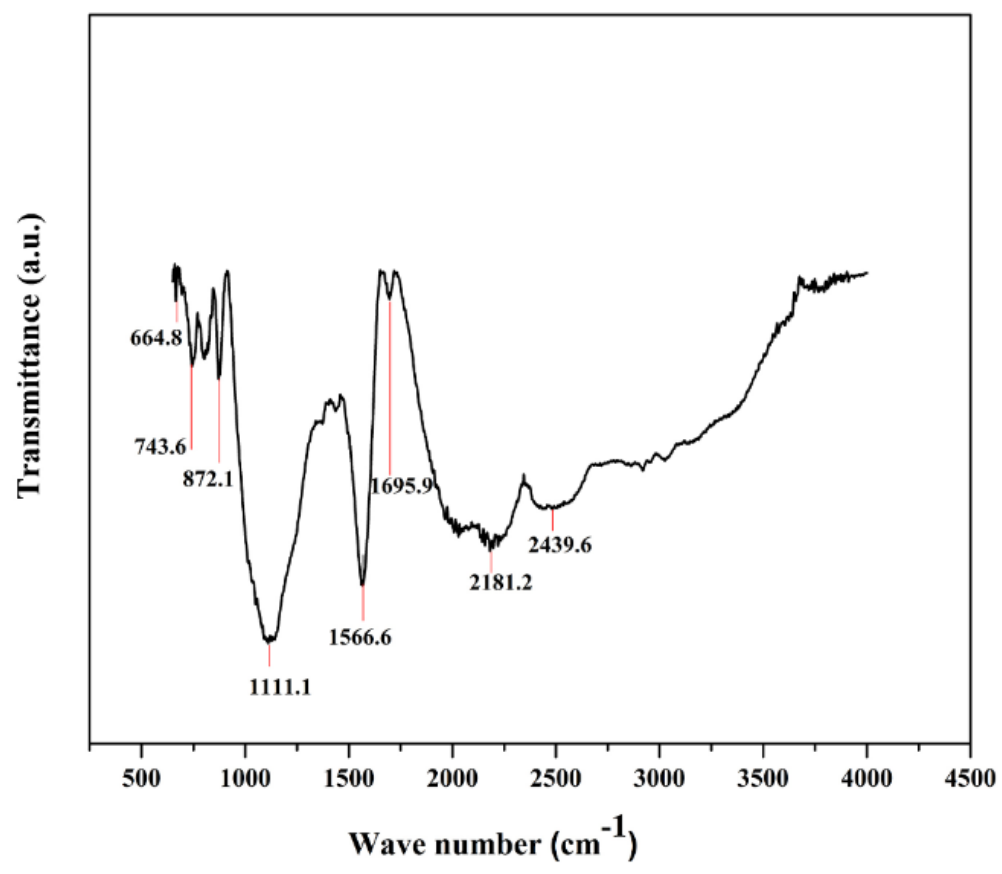

(a)

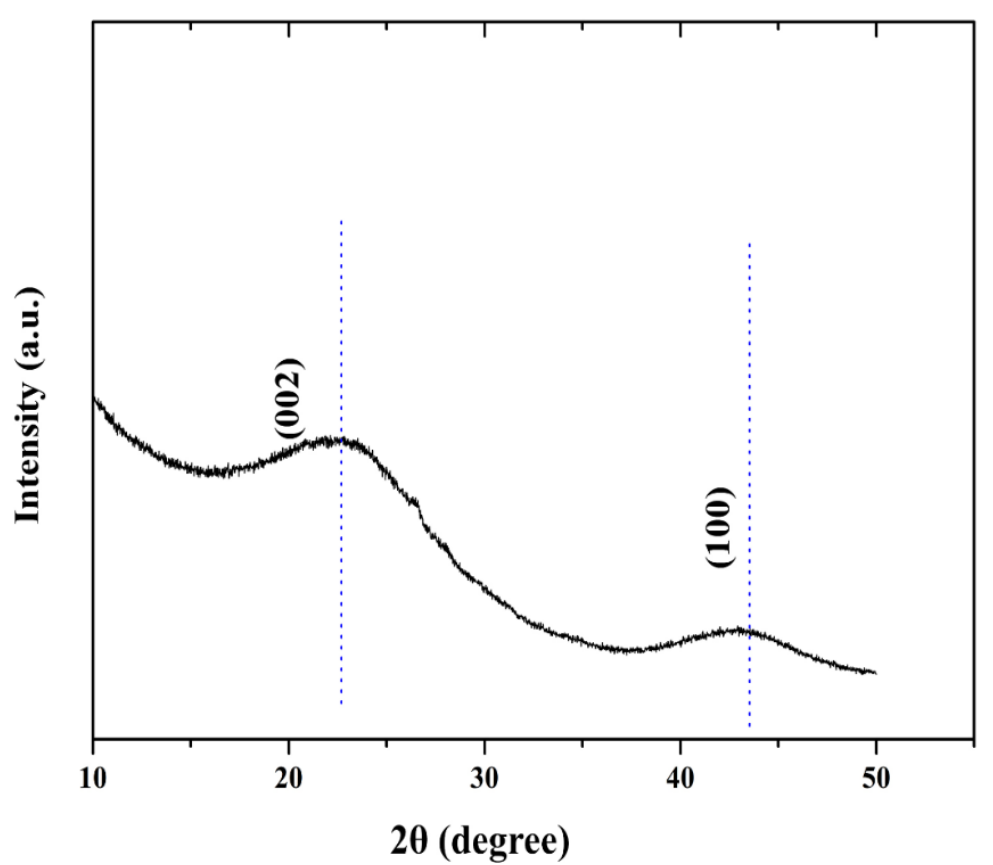

(b)

Figure 1 


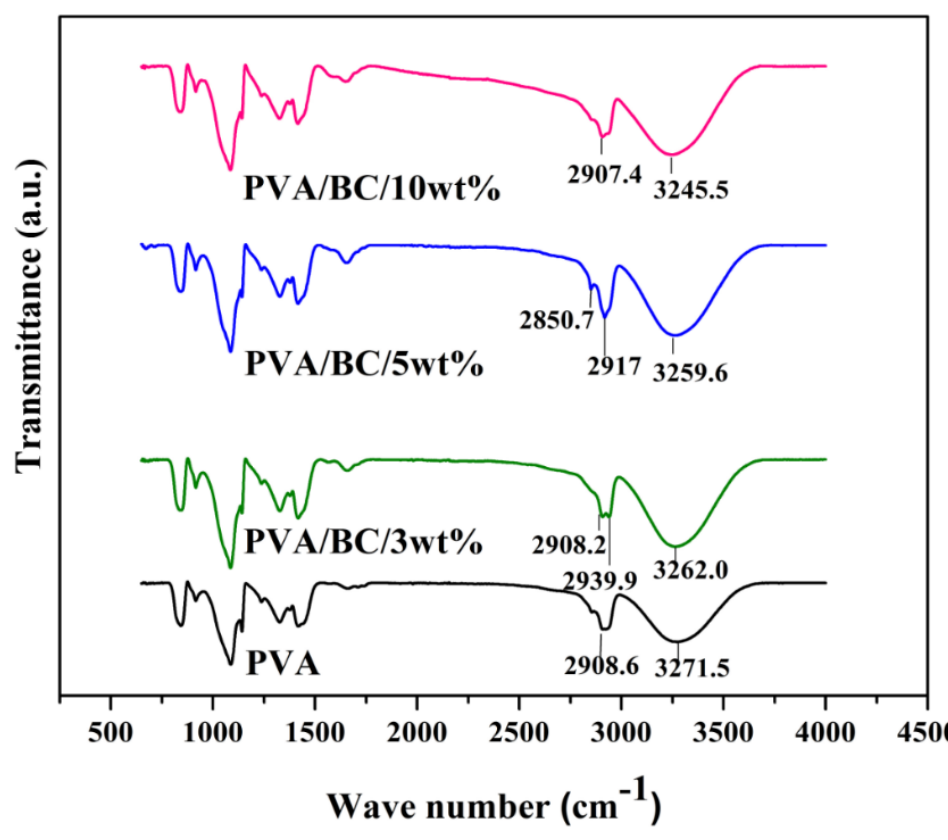

(a)

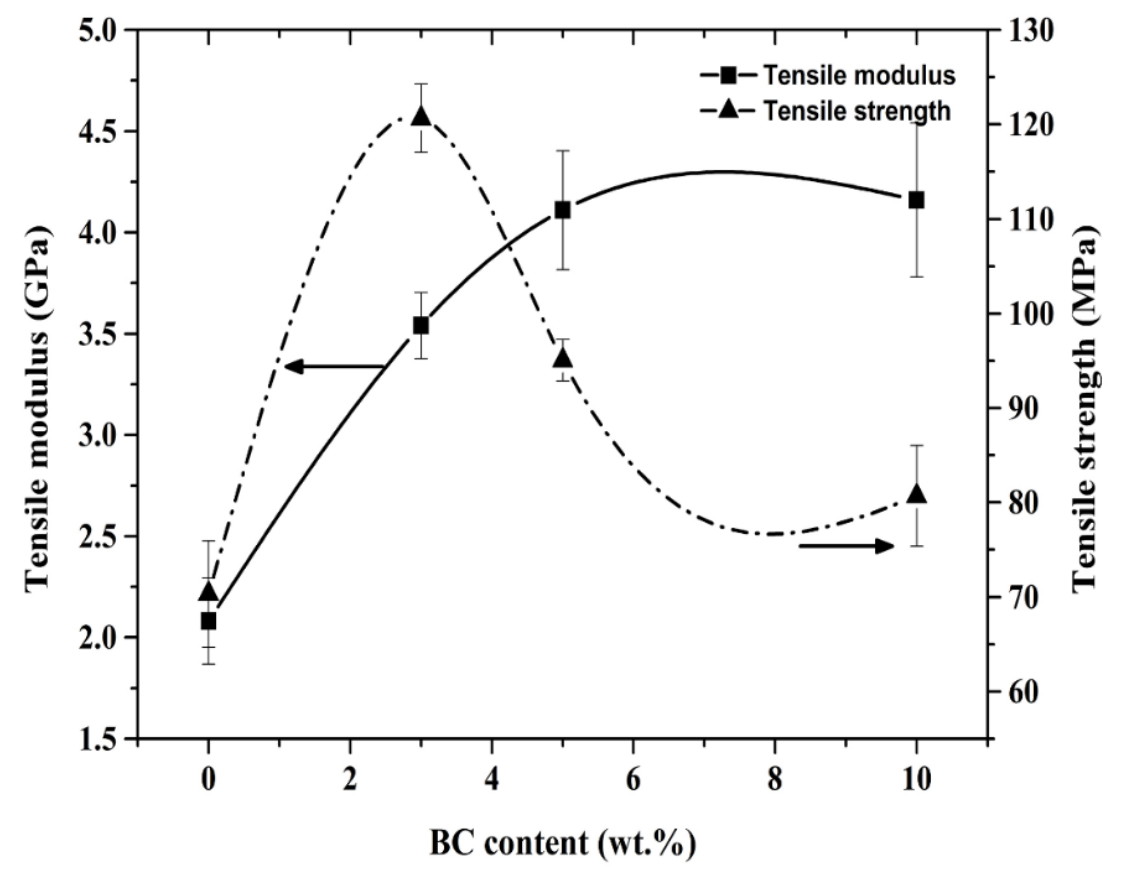

(c)

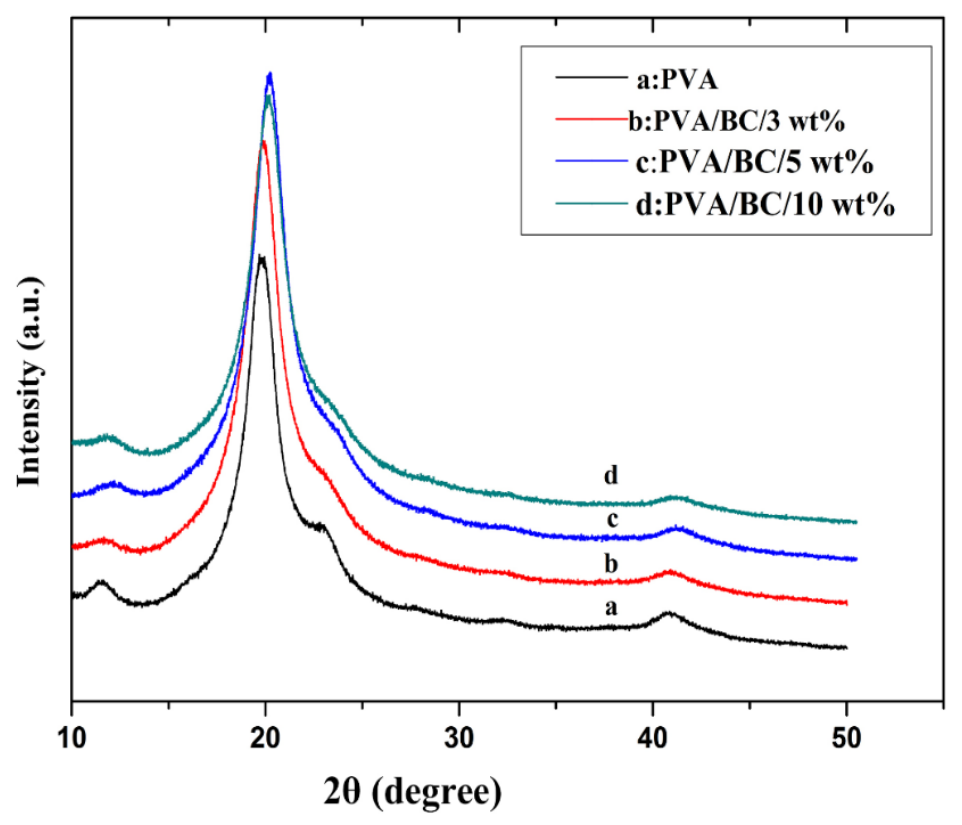

(b)

Figure 2 


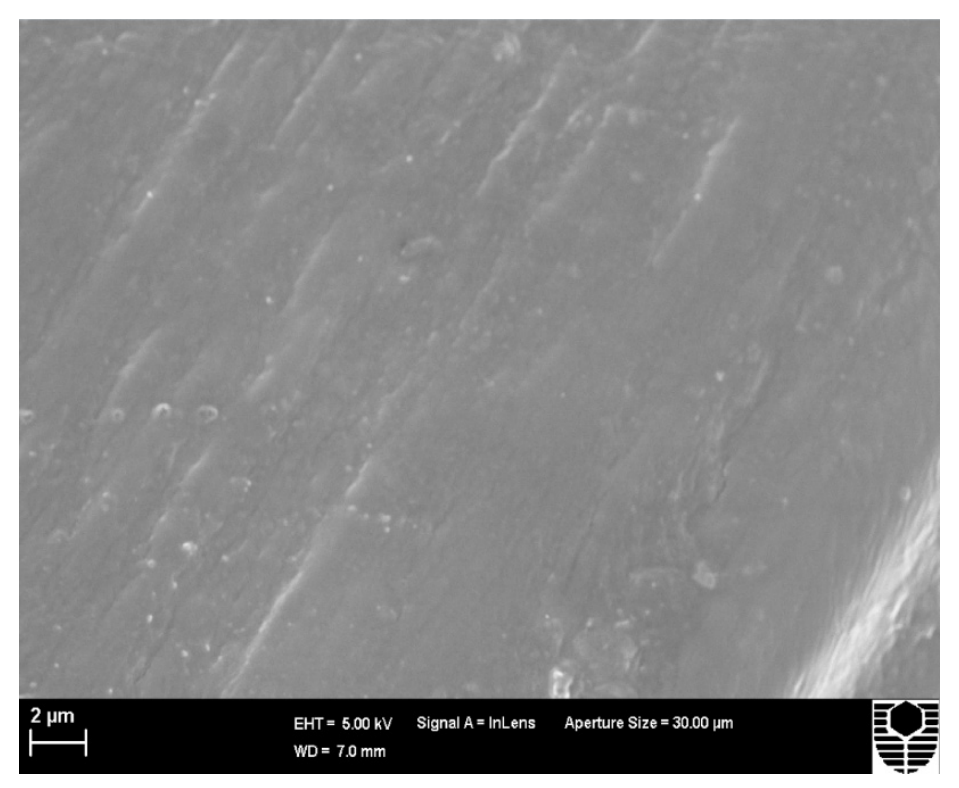

(a)

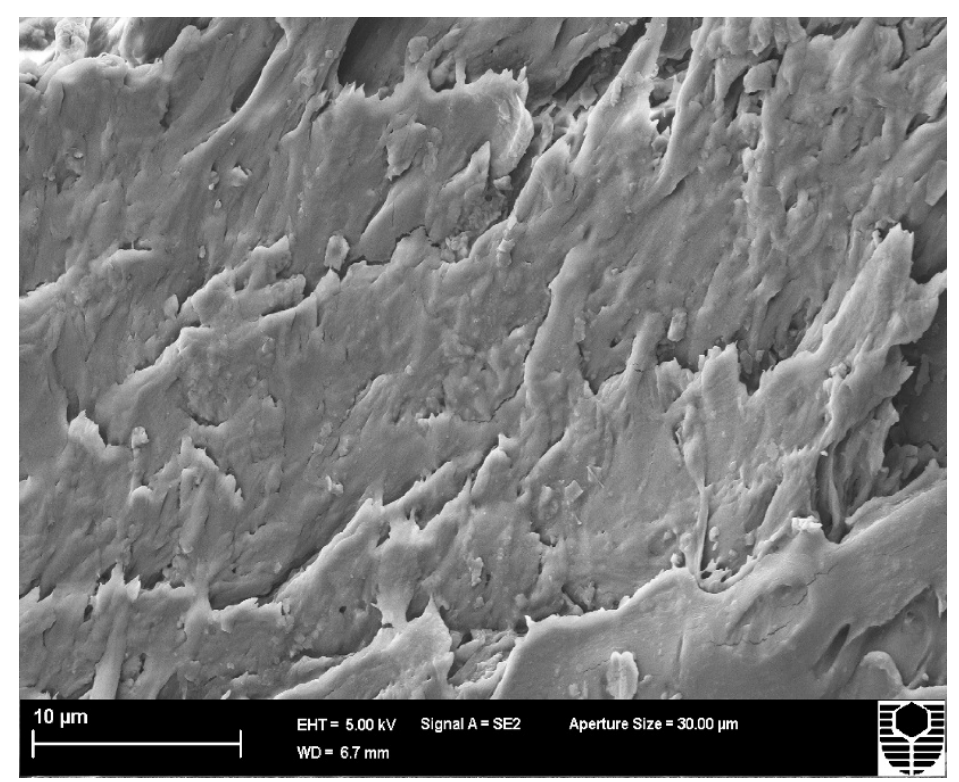

(c)

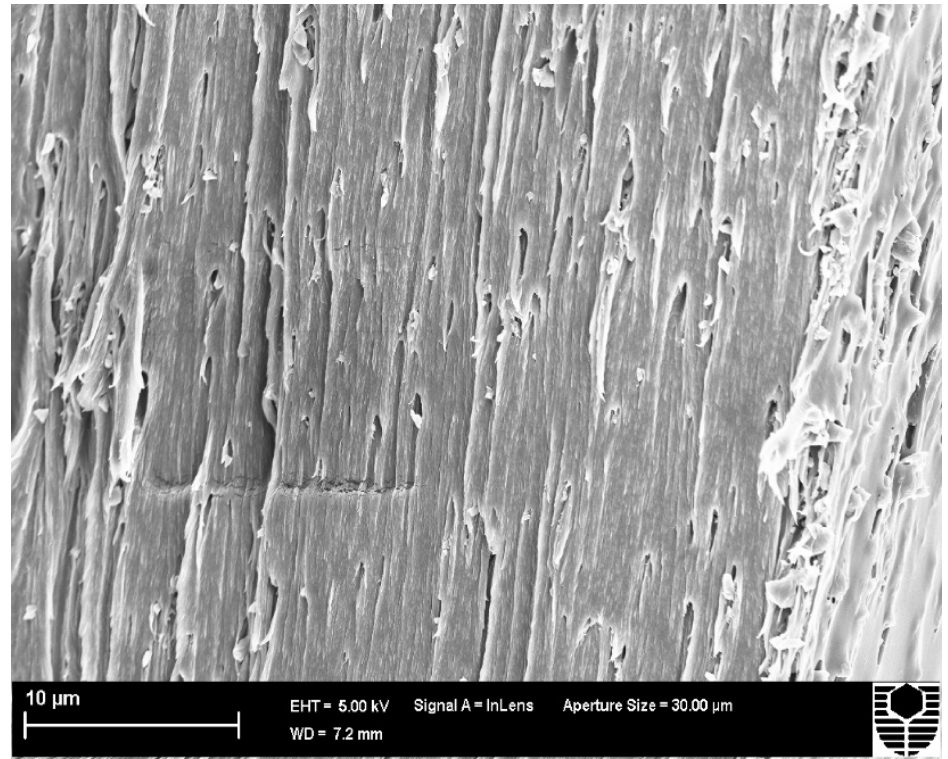

(b)

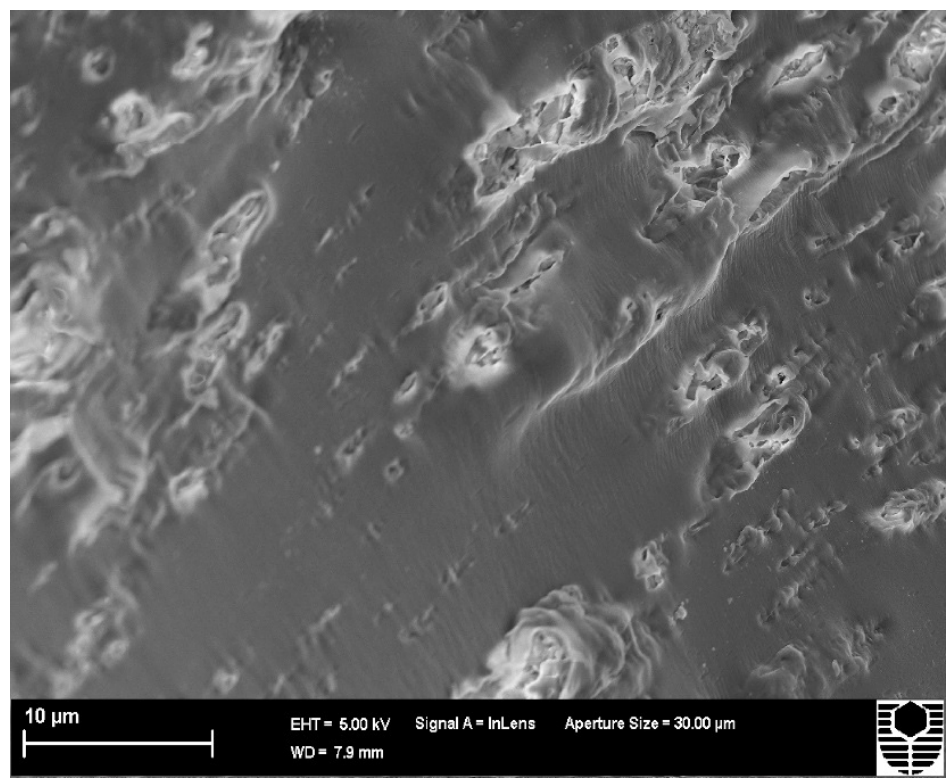

(d)

Figure 3 


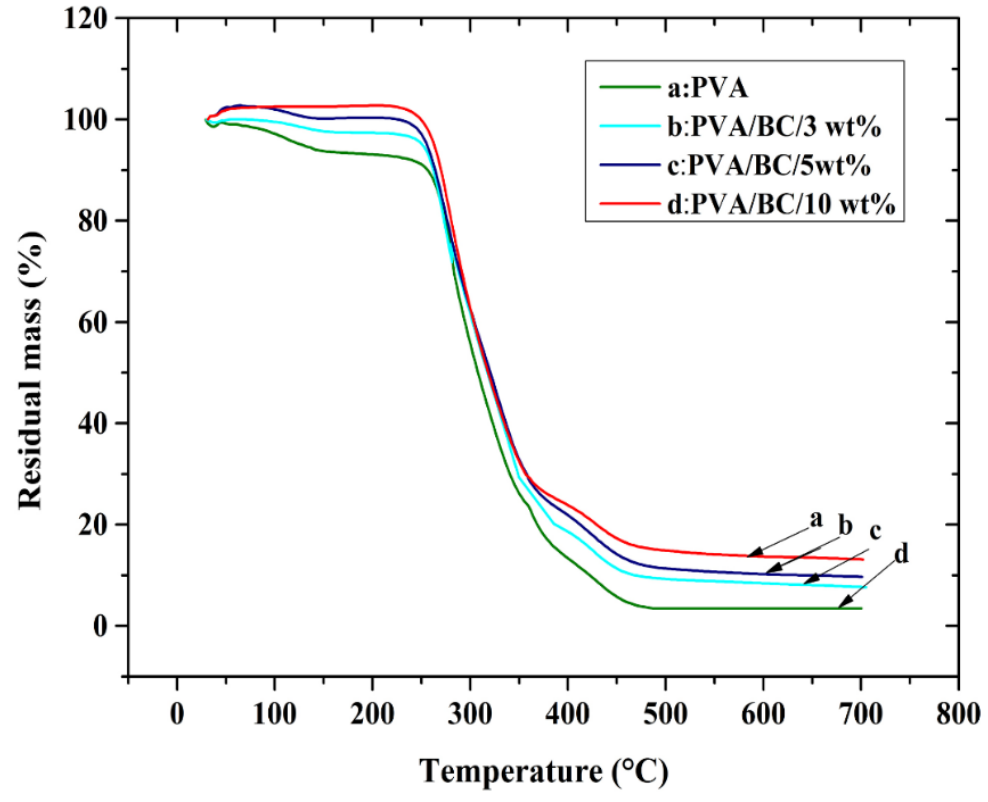

(a)

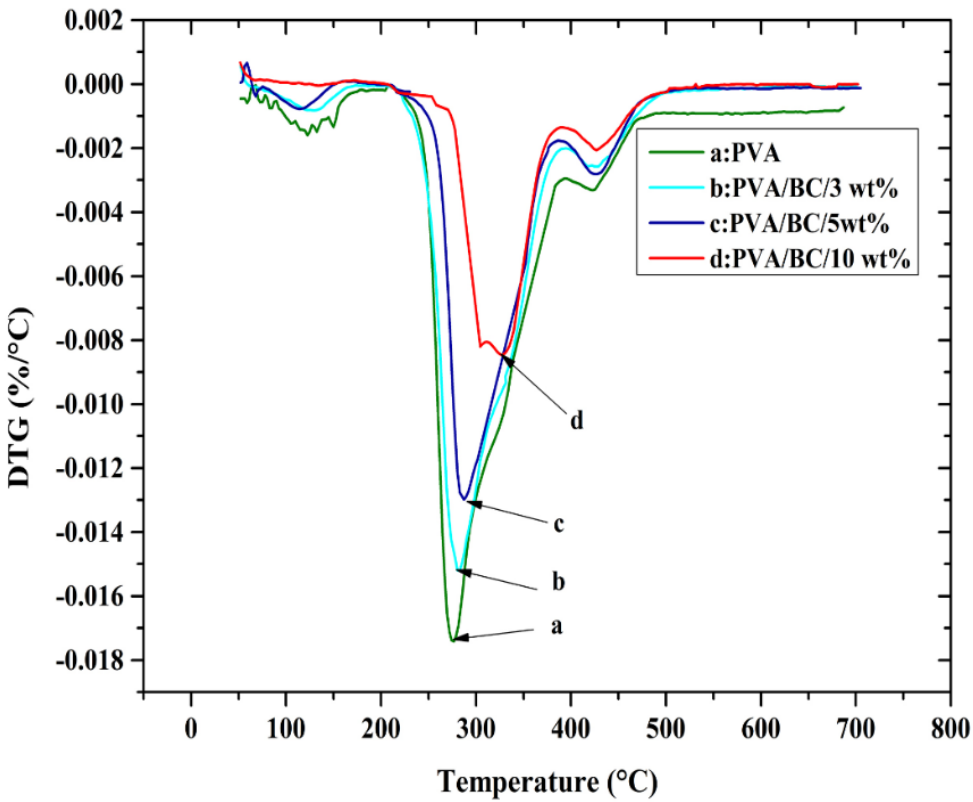

(b)

Figure 4 
Table 1 Mechanical properties of PVA and PVA/BC nanocomposite films

\begin{tabular}{cccc}
\hline & $\begin{array}{c}\text { Tensile modulus } \\
(\mathrm{GPa})\end{array}$ & $\begin{array}{c}\text { Tensile strength } \\
(\mathrm{MPa})\end{array}$ & $\begin{array}{c}\text { Elongation at break } \\
(\%)\end{array}$ \\
\hline Material sample & $2.08 \pm 0.53$ & $70.32 \pm 2.9$ & $14.60 \pm 2.3$ \\
$\mathrm{PVA} / \mathrm{BC} / 3 \mathrm{wt} \%$ & $3.54 \pm 0.52$ & $120.64 \pm 4.3$ & $6.93 \pm 2.6$ \\
$\mathrm{PVA} / \mathrm{BC} / 5 \mathrm{wt} \%$ & $4.11 \pm 0.39$ & $95.06 \pm 3.12$ & $5.98 \pm 2.19$ \\
$\mathrm{PVA} / \mathrm{BC} / 10 \mathrm{wt} \%$ & $4.16 \pm 0.41$ & $80.69 \pm 4.4$ & $4.88 \pm 1.26$ \\
\hline
\end{tabular}


Table 2 Thermal properties of PVA and PVA/BC nanocomposite films

\begin{tabular}{ccccc}
\hline Material sample & $T_{5 \%}\left({ }^{\circ} \mathrm{C}\right)$ & $T_{80 \%}\left({ }^{\circ} \mathrm{C}\right)$ & $T_{d}\left({ }^{\circ} \mathrm{C}\right)$ & Residue at $700^{\circ} \mathrm{C}(\mathrm{wt} \%)$ \\
\hline PVA & 200.15 & 363.5 & 275.23 & 3.4 \\
PVA/BC/3 wt $\%$ & 256.22 & 383.3 & 281.81 & 7.7 \\
PVA/BC/5 wt $\%$ & 258.78 & 410.12 & 287.93 & 9.7 \\
PVA/BC/10 wt $\%$ & 265.9 & 428.03 & 326.03 & 13.2 \\
\hline
\end{tabular}

Note $T_{5 \%}$ and $T_{80 \%}$ refer to decomposition temperatures at 5 and $80 \%$ mass loss taking place in TGA curves, respectively. $T_{d}$ is the maximum degradation temperature in DTG curves. 